\title{
Incorporating Carbon Capture and Storage Technologies in Integrated Assessment Models
}

\author{
J. R. McFarland and H. J. Herzog
}

\section{Introduction}

Over the past century, technological change has accounted for a significant portion of economic growth and is, in part, responsible for the dramatic increases in greenhouse gas emissions attendant with this growth. Despite this historic linkage between economic growth and greenhouse gas emissions, technological change also holds much promise for decoupling economic growth from emissions growth. Both the magnitude and rate of technological change toward low- or no-carbon emitting processes govern future anthropogenic emissions (IPCC, 2001). A multitude of integrated assessment models have been developed to characterize future greenhouse gas emission resulting from human economic activity, and to analyze the cost of policies for reducing such emissions (see e.g., Weyant and Hill, 1999). These models, containing various representations of technological change, form a key component of integrated climate policy analysis.

This paper examines the representation of carbon capture and storage (CCS) technologies, one form technological change, in integrated assessment models. As a test case, we use the MIT Emissions Prediction and Policy Analysis (EPPA) model, a computable general equilibrium (CGE) model of the world economy. EPPA simulates both economic growth and anthropogenic greenhouse gas emissions and performs a key role in the MIT Integrated Global System Model (Prinn et al., 1999). CGE models are the most complete in characterizing economy-wide interactions, including international trade, energy supply and demand, inter-industry supply and final demand for goods and services, and consumer demands. However, these models typically offer minimal technological detail compared to bottom-up engineering activity models (see e.g., van der Zwaan et al., 2002). As Jacoby, McFarland and Reilly (2003) note, specific technologies are but one form of technical change within the EPPA model. This paper highlights our efforts and future plans to represent low carbon-emitting, evolutionary technologies in the electricity sector of a CGE model ${ }^{1}$.

The broad class of CCS technologies includes all systems that harness $\mathrm{CO}_{2}$ from industrial processes or the air and sequester the $\mathrm{CO}_{2}$ in geologic reservoirs, the deep ocean, or biomass. The CCS technologies represented in this paper apply only to the capture and storage of $\mathrm{CO}_{2}$ from electric power plants. The electric power sector accounts for a substantial portion of greenhouse gas emissions in the developed world and a growing fraction in developing countries. In the U.S., electricity generation accounts for about one-third of all greenhouse gas emissions. Herein we describe the representation of three electricity generation options that compete with existing electricity generation technologies in the EPPA model. The three new power generation technologies are: 1) a natural gas combined cycle technology (advanced gas) without carbon capture and storage, 2) a natural gas combined cycle technology with carbon capture and storage

\footnotetext{
${ }^{1}$ For a more economically rigorous presentation of incorporating CCS technologies in CGE models, refer to McFarland, Reilly, and Herzog (2003).
} 
(gas capture), and 3) an integrated coal gasification technology with carbon capture and storage (coal capture). These compete in the EPPA model's electricity sector with conventional fossil generation, nuclear, hydro, wind, and biomass power generation. This paper addresses three main issues with representing CCS technologies in a top-down model: proper characterization of the technical system, translation of bottom-up engineering information into a CGE model, and the portrayal of factors that affect technology adoption rates. Many of the lessons learned in our research and the cost and performance data that have been developed can be applied to other integrated assessment models.

Section 2 describes both the framework of the EPPA model and the bottom-up engineering cost models of technical systems that are to be represented within it. The translation of bottom-up engineering cost models into EPPA's general equilibrium framework is handled in Section 3. These sections summarize our efforts to characterize the relative economics of technologies competing in the electricity sector. Having dealt with the attributes that determine the economic attractiveness of a technology in Sections 2 and 3, Section 4 examines the factors that affect the rate of technology adoption, reviews their treatment in integrated assessment models, and outlines areas of further research that we are conducting.

\section{Characterizing Technology Costs Using Bottom-up Information}

Incorporation of novel technologies into top-down models requires a complete accounting and characterization of costs that is consistent with the engineering system in which the technology operates as well the model's structure and underlying data. This section begins with a brief description of the EPPA model, previewing the final economic analysis framework. It is followed by a characterization of the individual technologies and the economic and physical systems in which they operate.

\subsection{Overview of the MIT EPPA model}

The EPPA model is a recursive dynamic multi-regional general equilibrium model of the world economy developed for the analysis of climate change policy (Babiker, et al., 2001). Version 3 of the model is built on a comprehensive energy-economy data set, GTAP-E as described by Hertel (1997), that accommodates a consistent representation of energy markets in physical units as well as detailed accounts of regional production and bilateral trade flows ${ }^{2}$. The base year for the model is 1995, and it is solved recursively at 5-year intervals through 2100 to capture the long-term dynamics of resource scarcity and capital stock turnover. EPPA consists of twelve regions, which are linked by international trade, nine production sectors, and a representative consumer for each region as shown in Table 1. Capital, labor, and a factor resource for each fossil fuel and a land resource for agriculture comprise the primary factors of production. As illustrated below in Section 3, new technologies must be parameterized in terms of these factors of production, specifically capital, labor, and fuel for CCS technologies.

\footnotetext{
${ }^{2}$ EPPA Version 4 is now in use (see Jacoby, Reilly, and McFarland, 2003 for a summary of the changes), but CCS technologies are not yet incorporated in the new model.
} 
Table 1. EPPA regions, sectors, and factors of production

\begin{tabular}{|l|l|}
\hline Regions & $\begin{array}{l}\text { Annex B (United States, Japan, European Union, Other OECD, Eastern European } \\
\text { Associates, Former Soviet Union) and } \\
\text { Non-Annex B (Brazil, China, India, Energy Exporting Countries, Dynamic Asian } \\
\text { Economies, and Rest of World). }\end{array}$ \\
\hline $\begin{array}{l}\text { Production } \\
\text { Sectors }\end{array}$ & $\begin{array}{l}\text { Coal, Oil, Refined Oil, Gas, Electricity, Energy Intensive Industries, Agriculture, } \\
\text { Investment, and Other Industries. }\end{array}$ \\
\hline Primary Factors & $\begin{array}{l}\text { Labor, Capital, and Fixed Factor resources for coal, oil, gas, shale oil, and } \\
\text { agriculture. }\end{array}$ \\
\hline
\end{tabular}

\subsection{Defining a Representative Technology}

Integrated assessment models contain a high level of economic and environmental aggregation. This concept is also extended to representations of technology. Top-down models, and even to some degree bottom-up models (see e.g., Fujii and Yamaji, 1998) aggregate what in reality is a range of individual technologies operating in multiple markets into a single representative technology. For instance, the EPPA model contains eight of technologies in the electric power sector: conventional fossil fuel, natural gas combined cycle, nuclear, hydro, wind and solar, biomass, gas capture and coal capture. Each technology represents a general composite of individual technologies that may vary by manufacturer, market, and vintage. Recognizing a lack of perfect foresight into the particular configuration of CCS plant that might be used in the future, we base the bottom-up engineering cost analysis on the most economic versions known today. ${ }^{3}$ Based on a study by David and Herzog (2000) of the most promising technological options, we focus on natural gas combined cycle generation with capture via amine scrubbing of the flue gas, and integrated coal gasification combined cycle generation with pre-combustion capture of the carbon dioxide $\left(\mathrm{CO}_{2}\right)$.

\subsection{Establishing Costs of Technologies within Systems}

In characterizing CCS technology costs, we derive from bottom-up engineering models the total costs of electricity as delivered to the consumer. This allows for a consistent comparison across competing technologies, which are also specified by end-user costs within the EPPA modeling framework. We base the generation cost, efficiency, and carbon emissions of CCS technologies on the bottom-up engineering estimates by David and Herzog (2000). Their analysis averages several generation cost studies from the U.S. and Europe. The generation cost data presented herein reflects their projections of CCS technology costs after modest technical improvements anticipated by 2012. In addition to electricity generation itself, three other costs must be included to obtain the cost to the end-user: transmission and distribution of electricity, carbon transport and storage, and $\mathrm{CO}_{2}$ emission permits to cover the portion of carbon that is not captured. Equation 1 summarizes the total cost accounting for CCS technologies used for electricity generation:

$C_{\text {Electricity }}=C_{\text {Generation }}+C_{T \& D}+C_{\text {Sequestration }}+\kappa P_{\text {Carbon }}$

\footnotetext{
${ }^{3}$ Models such as Pacific Northwest Laboratory's Second Generation Model (Sands, 2003) account for variability in generation costs within a technology group by specifying the variance in a logistic production function.
} 
where $C$ denotes cost, the subscript refers to the cost category, and the constant $\kappa$ is the technology-specific rate of carbon emitted per unit of electricity produced. Electricity transmission and distribution cost information is based upon a survey by the Federal Energy Regulatory Commission (U.S. Department of Energy, 1999). $\mathrm{CO}_{2}$ injection and storage costs are conservatively assumed to be $\$ 37$ per ton of carbon $(\$ / t C)$ (Bock et al., 2003) ${ }^{4}$. Formulated as such, Equation 1 makes explicit the dependence of the cost of electricity on the price that must be paid for any carbon that is emitted to the atmosphere by the technology as even capture technologies typically do not capture $100 \%$ of the carbon in the fuel. A nominal capture efficiency of $90 \%$, used by David and Herzog (2000), is adopted here. The cost information contained in Table 2 below offers a representative illustration of the cost accounting for the advanced gas, gas capture, and coal capture technologies at fixed fuel prices and plant capacity factors ${ }^{5}$.

Table 2. Electricity cost breakdown by technology (cents/kWh)

\begin{tabular}{|c|c|c|c|c|c|}
\hline Technology & $\begin{array}{c}\text { Cost of } \\
\text { Generation }\end{array}$ & $\begin{array}{c}\text { Cost of } \\
\text { transmission and } \\
\text { distribution }\end{array}$ & $\begin{array}{c}\text { Cost of } \\
\text { Sequestration }\end{array}$ & $\begin{array}{c}\text { Total Cost } \\
\text { Excluding } \\
\text { Emissions } \\
\text { Penalty }\end{array}$ & $\begin{array}{c}\text { Emissions } \\
\text { Coefficient } \\
\kappa \\
(\mathrm{kg} \mathrm{C} / \mathrm{kWh})\end{array}$ \\
\hline $\begin{array}{c}\text { Advanced Gas } \\
\text { (NGCC) }\end{array}$ & 3.10 & 2.43 & 0 & 5.53 & 0.092 \\
\hline Gas capture & 4.33 & 2.43 & 0.34 & 7.10 & 0.010 \\
\hline Coal capture & 5.15 & 2.43 & 0.66 & 8.23 & 0.020 \\
\hline
\end{tabular}

\subsection{Plant Dispatch}

Two characteristics of the electric power sector make plant dispatch a critical parameter in assessing the economics of CCS technologies. First, unlike most other goods electricity is produced and consumed instantaneously. It cannot be stored without significant expense and power loss. Second, the demand for electricity changes throughout the day. Demand is highest during business hours and into the early evening. Figure 1 identifies three categories of demand based on annual dispatch and capacity cost in the U.S.: peak power which dispatches less than $6 \%$ of the year (about $500 \mathrm{hr} / \mathrm{yr}$ ), intermediate power which dispatches up to $55 \%$ of the year (4800 hr/yr), and base power which dispatches continuously (Speakes, 2002).

\footnotetext{
${ }^{4}$ Based on a transport distance of 100 kilometers.

${ }^{5}$ A capacity factor of $75 \%$ is assumed across all technologies. Fuel costs for the gas technologies are $\$ 2.93 / \mathrm{mmBtu}$ and $\$ 1.24 / \mathrm{mmBtu}$ for coal.
} 


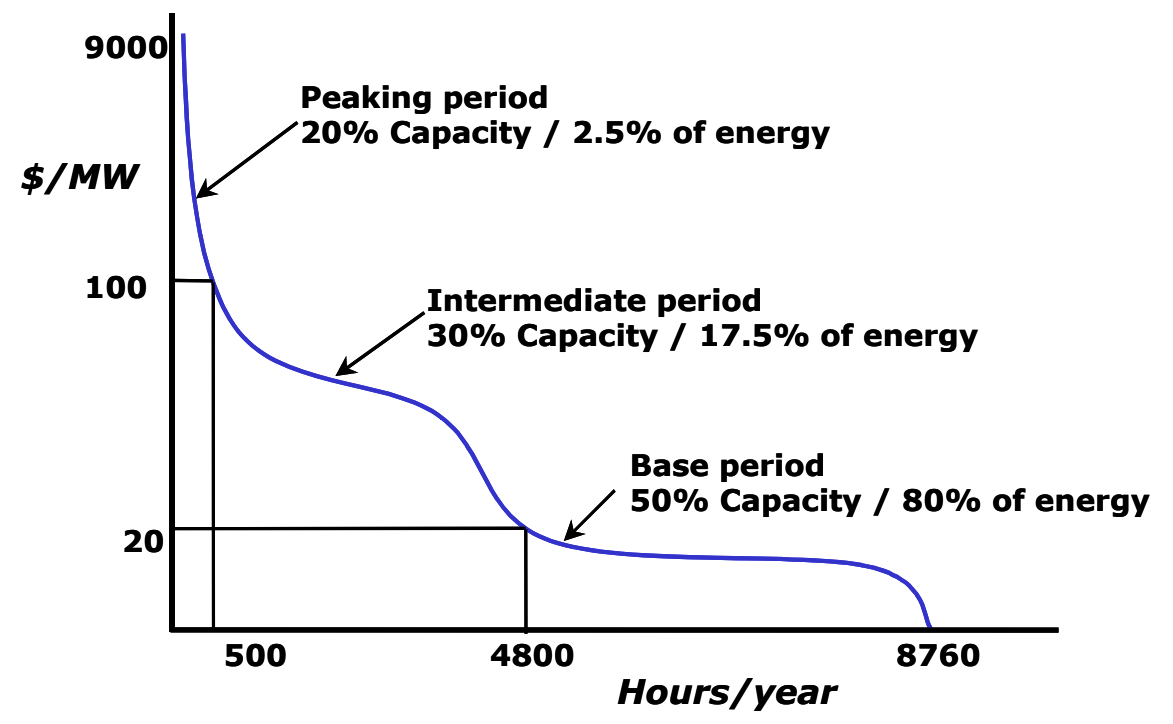

Figure 1. Capacity Cost vs. Annual Dispatch for the U.S. (Speakes, 2002)

The frequency with which a plant is dispatched has a significant impact upon the ability of a plant to recover fixed capital costs. This in turn affects the types of plants constructed and dispatched to meet demand for different segments of the load curve. In deregulated markets, capital intensive coal and nuclear plants typically fill base load capacity, natural gas combined cycle plants fill intermediate load capacity, and simple cycle gas turbines provide peaking capacity. In a competitive market, plant dispatch is determined by marginal operating cost with the low marginal cost plants dispatched first. However, the decision to build new capacity is based upon expected profits, which are determined by average total costs. Therefore, the economics of investment decisions are dependant upon dispatch when a technology does not have both the lowest average total cost and the lowest marginal operating cost.

This situation arises for investment decisions between gas- and coal-fired plants. Figure 2 below shows the average cost (AC) and marginal cost (MC) of electricity for two technologies as a function of capacity factor ${ }^{6}$ : gas capture and coal capture. For equivalent capacity factors, the average cost of the gas capture plant is cheaper to operate than the coal capture plant and suggests that the gas plant would be more profitable. Yet, the marginal cost for the coal capture plant is 0.6 cents $/ \mathrm{kWh}$ less expensive than the gas capture plant largely reflecting the lower fuel cost of coal versus gas ${ }^{7}$. With a lower marginal cost, the coal capture technology would likely have a higher dispatch level and, therefore, capacity factor than the gas capture technology. Assuming the lower marginal cost coal capture plant is dispatched at a higher rate to yield a capacity factor of $85 \%$, the gas capture technology would need a capacity factor of greater than $60 \%$ to be economically viable on an average cost basis. Thus for base load generation, the coal capture technology would have better economics than the gas capture plant. Gas capture plants,

\footnotetext{
${ }^{6}$ Capacity factor is the percentage of time a plant operates in a given year. This parameter is a product of plant availability and dispatch.

${ }^{7}$ Delivered gas and coal prices used in this calculation are $\$ 3.00 / \mathrm{mmBtu}$ and $\$ 1.24 / \mathrm{mmBtu}$ respectively. The difference in marginal cost rises to 1.3 cents $/ \mathrm{kWh}$ at gas prices of $\$ 4.00 / \mathrm{mmBtu}$. The figure assumes a carbon price of $\$ 200 / \mathrm{tC}$, but this does not have a relative effect on the average or marginal costs.
} 
however, are more likely to be used as intermediate load. At capacity factors of $40 \%$ to $50 \%$, gas capture plants are 1.0 to 1.5 cents/kWh cheaper than the coal capture plants on an average cost basis.

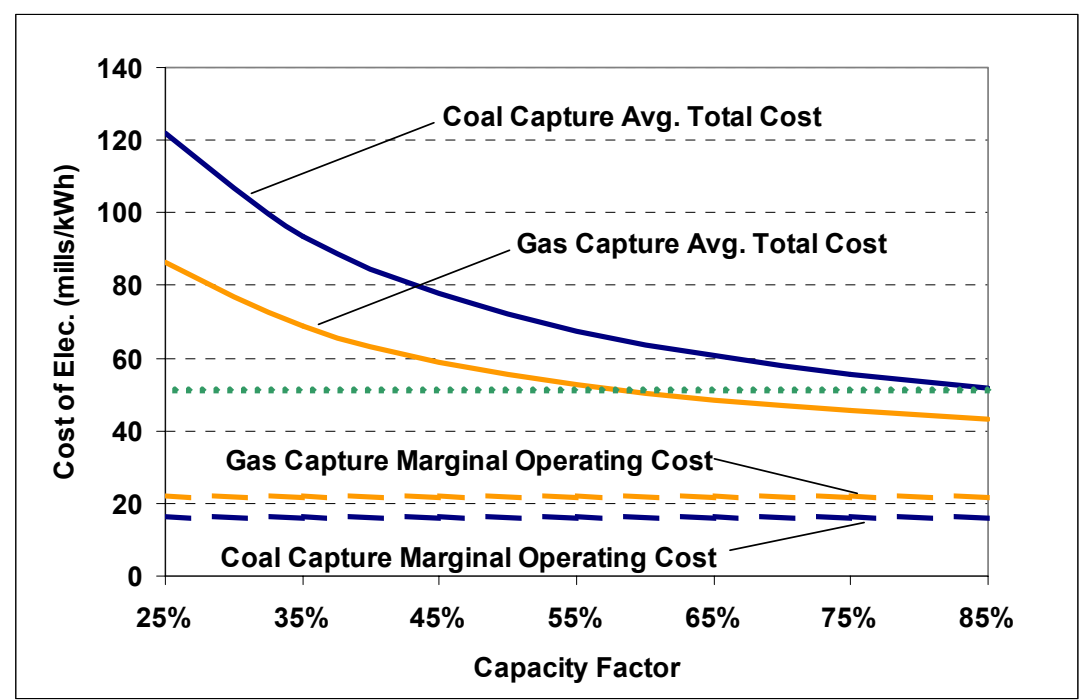

Figure 2. Cost of Electricity Generation for Pulverized Coal and NGCC Plants as a Function of Capacity Factor

Simplifying assumptions are required to reflect the effects of load dispatch in highly aggregated CGE models. Although bottom-up activity models have been used to address the economic dispatch of competing generating technologies (see e.g., Johnson, 2002, Johnson and Keith, 2003), CGE models lack the grid-specific detail required by a bottom-up approach. Two approaches have been used to incorporate dispatch into top-down models. The first approach, used in EPPA, relies on dispatch estimates from bottom-up activity models to compute cost information in engineering cost models. The second approach introduces separate production sectors for peak and intermediate loads and for base loads.

Using the EPPA model and a stylized example, we illustrate the importance of economic dispatch to technology selection. Figures $3 \mathrm{a}$ and $3 \mathrm{~b}$ below depict the energy consumption in the US electric power sector by technology under different dispatch assumptions for gas capture and coal capture. For both scenarios, the carbon tax is assumed to peak at $\$ 440$ per metric ton of carbon after 2060 with a long-run wellhead price of natural gas of $\$ 2.40$ per million BTU after $2010^{8}$. The first scenario (Figure 3a) assumes gas capture and coal capture technologies both have capacity factors of $75 \%$, despite a lower marginal cost for the coal capture technology. In this scenario, the gas capture technology becomes the dominant electricity generating technology in the US and accounts for $50 \%$ of electricity generation by 2080 . In the second scenario (Figure $3 \mathrm{~b}$ ), the coal capture technology, due to a lower marginal cost, is assumed to have a capacity factor of $80 \%$ while the gas capture technology has a capacity factor of $60 \%$ reflecting its use in intermediate load applications. Using capacity factors typically found in bottom-up models, coal

\footnotetext{
${ }^{8}$ While much lower than current prices, this natural gas price is consistent with abundant global natural gas supplies and significant importation on liquefied natural gas as evidenced in Adelman and Lynch (2002).
} 
capture generates the bulk of US electricity. The intuition is that coal plants with lower marginal costs would always be built ahead of gas capture plants. Note that removing the option to produce electricity with the gas capture technology has the general equilibrium effect of raising long-run electricity costs and suppressing demand as shown by the 20 EJ reduction in primary energy input into the electricity sector.
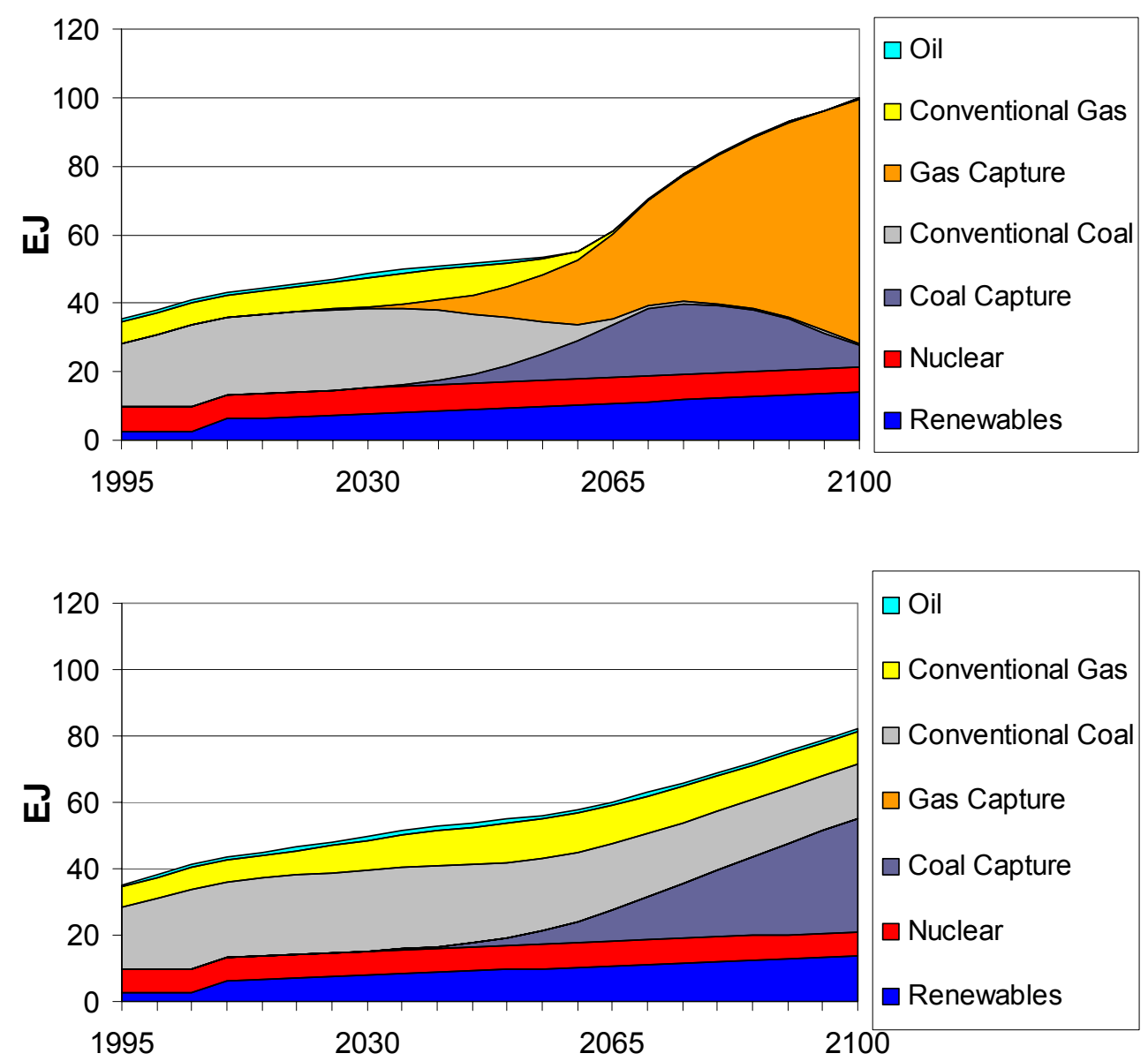

Figures 3a and 3b. Energy Consumption in the US Electric Sector (primary equivalents) for Gas Capture and Coal Capture Capacity Factors of 75\%:75\% (3a) and 60\%:80\% (3b).

The alternative approach used by Sands (2003) divides the electric sector into two sub-sectors: base power and peak plus intermediate power. Each sub-sector contains a separate set of technologies, and the average cost of each technology is calculated at capacity factors typical for that sub-sector. Although computationally and data intensive, this approach may more accurately characterize the investment decisions for the roughly $20 \%$ to $30 \%$ of total electricity generated during intermediate and peak loads. 


\section{Translating Bottom-Up Information Into Top-Down Models}

Having accounted for the relevant bottom-up technology costs, we now demonstrate how to translate these technology costs for application in a top-down macro-economic model. This section reviews three aspects of this translation: converting bottom-up engineering costs into factors of production, specifying elasticities of substitution between factors of production, and specifying costs relative to existing technologies. ${ }^{9}$

\subsection{Transforming Engineering Costs into Factors of Production}

In CGE models, industries and the technologies underlying them, are represented as production functions. The economic framework in EPPA combines factor resources (capital, labor, energy, and land) to produce intermediate goods and economic output. An important step in representing individual technologies within EPPA is translating bottom-up engineering inputs into the factors of production and intermediate goods that are tracked in the general equilibrium economic framework. For CCS technologies, this involves calculating the shares, in dollar terms, of capital, labor, and fuel that go into generating a unit of electricity for a given technology.

The bottom-up cost data for the cost components listed in Equation 1 are categorized, in engineering terms, as capital, fuel, operations and maintenance, and administrative and general. From these data, we estimate input shares of capital, labor, and fuel, that are then used as the share parameters (see Table 3 below) in a constant elasticity of substitution production function. Labor factor shares in EPPA are calculated as the fraction of total cost attributable to operations and maintenance for generation, administrative and general for transmission and distribution, and $10 \%$ of the costs of carbon storage. Capital factor shares are based upon the share of capital required for generation, transmission and distribution, and $90 \%$ of the costs of carbon storage.

The shares of capital and fuel inputs offer insight into how changes in various factor prices affect each the cost of each technology. As shown in Table 3, the advanced gas technology without capture and sequestration requires the lowest share of capital at 0.49 , but the highest share of fuel at 0.30. The addition of the capital intensive CCS technology to an NGCC plant raises the capital share to 0.54 while reducing the fuel share to 0.26 even though capturing and storing the $\mathrm{CO}_{2}$ requires more absolute energy per $\mathrm{kWh}$ of electricity produced. Capital represents an even greater input share for the coal capture technology at 0.66 . A fuel share of 0.12 reflects both low coal prices and the capital-intensive nature of the technology. Thus, the gas technologies are sensitive to changes in fuel prices while the coal capture technology is more sensitive to the price of capital. Across the three technologies, labor shares fall within a narrow range of 0.20 to 0.22 and reflect the engineering cost categories of operations, maintenance, general and administrative.

\footnotetext{
${ }^{9}$ This section draws heavily from McFarland, Reilly, and Herzog (2003), which offers a more detailed and economically rigorous description.
} 
Table 3. Factor shares of capital, labor, and fuel by cost component

\begin{tabular}{|c|c|c|c|c|c|c|c|c|c|}
\hline & \multicolumn{7}{|c|}{ Cost Components } & & \\
\hline Technology & \multicolumn{2}{|c|}{ Generation } & \multicolumn{2}{|c|}{$\begin{array}{l}\text { Transmission \& } \\
\text { Distribution }\end{array}$} & \multicolumn{2}{|c|}{$\begin{array}{c}\text { Carbon Transport } \\
\text { and Storage }\end{array}$} & Fuel & \multicolumn{2}{|c|}{$\begin{array}{c}\text { Capital and Labor } \\
\text { Subtotals }\end{array}$} \\
\hline Factor & Capital & Labor & Capital & Labor & Capital & Labor & $\begin{array}{c}\text { Gas or } \\
\text { Coal }\end{array}$ & Capital & Labor \\
\hline Advanced Gas & 0.22 & 0.04 & 0.27 & 0.17 & NA & NA & 0.30 & 0.49 & 0.21 \\
\hline Gas capture & 0.29 & 0.06 & 0.21 & 0.13 & 0.04 & 0.00 & 0.26 & 0.54 & 0.20 \\
\hline Coal capture & 0.40 & 0.10 & 0.18 & 0.11 & 0.07 & 0.01 & 0.12 & 0.66 & 0.22 \\
\hline
\end{tabular}

\subsection{Characterizing Input Substitution}

Having determined the shares of factor inputs required by a technology, we specify the ability to substitute between the different factors of production in generating electricity. By specifying elasticities of substitution between different factors of production, we are able to model economic processes that trade-off high priced factors of production for lower priced ones. One can see such activities at work in the electric power sector today. Countries with high fuel costs such as Japan tend to invest in power generating technologies that are more efficient than those found in other countries. However, these investments necessitate additional capital and operations and maintenance outlays for cleaner, more efficient technologies. Furthermore, countries with a low cost of labor relative to capital have an economic incentive to rely heavily on manual labor rather than equipment and monitoring devices for operations and maintenance activities.

Using our understanding of the engineering systems, we specify elasticities of substitution within and between the factors in each cost component outlined in Table 3 . The nesting structure of the CES production functions used to model the CCS technologies is illustrated in Figure 4. Factors or bundles of factors connected at acute angles have elasticities of substitution greater than zero and those connected at right angles are Leontief, i.e. with substitution elasticities of zero. At the lowest level of the production structure, elasticities of substitution are specified between capital and labor in three areas: generation, transmission and distribution of electricity, and the transport and storage of $\mathrm{CO}_{2}$. In generating electricity, as noted above, labor may be substituted for capital at the margin via the operations (e.g., automated process control versus manual controls) and maintenance programs at a power plant (e.g., use of specialized repair equipment versus additional labor). Similarly, in the transmission and distribution of electricity, there are tradeoffs between installing and maintaining such a system with specialized equipment and monitoring versus a labor-intensive approach which requires additional workers (e.g., automated monitoring of consumption versus meter-reading). This analogy readily extends to the ability to substitute between labor and capital in installing and operating a $\mathrm{CO}_{2}$ transmission, storage, and monitoring network. In all of these cases, the elasticity of substitution used is less than unity (0.8).

The fuel and sequestration branch of Figure 4 depicts CCS technologies with two fuel inputs. One represents the portion of total fuel input whose $\mathrm{CO}_{2}$ is captured. The other represents the smaller amount of fuel whose $\mathrm{CO}_{2}$ is vented and is subject to emissions penalties (e.g., a carbon 
tax or emission permit). These two inputs are used in fixed proportions along with the capitallabor bundle for the transport and storage of $\mathrm{CO}_{2}{ }^{10}$.

The elasticity of substitution between the generation, transmission, and distribution bundle and the fuel and sequestration bundle controls the degree to which changes in relative prices affect thermodynamic efficiency. For elasticities of substitution greater than zero, price increases of fuels or $\mathrm{CO}_{2}$ relative to capital and labor lead to a greater use of capital and labor to produce a unit of electricity thus improving thermal efficiency. An iterative approach is used to identify an elasticity that allows for gradual improvements in thermodynamic efficiency under increasing costs of fossil fuels and carbon emissions without exceeding plausible physical limits imposed by the laws of thermodynamics. For the technologies considered herein, we use a substitution elasticity of 0.02 at this point of the production structure.

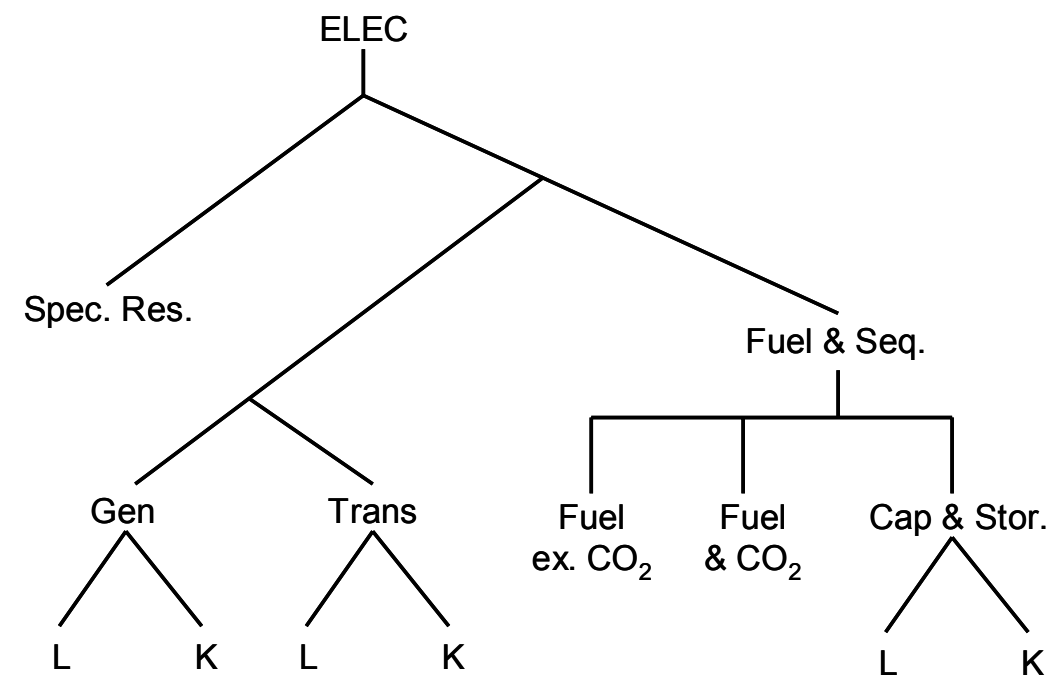

Figure 4. Production structure of CCS technologies.

The top level of substitution occurs between the capital-labor-energy bundle and a resource factor that is used to control the short-run penetration rate of the technology. The resource factor may be thought of as specialized engineering, capital, and regulatory resources required for this particular technology. The specification of this factor is reviewed in Section 4.3 below.

\subsection{Specifying the Relative Economics of Technologies}

The final step in specifying CCS technologies in a top-down model involves correctly specifying the relative costs of technologies in the base year. This ensures that technologies are first adopted at the appropriate relative prices. In the base year of the model, 1995, the three technologies listed in Table 4 compete with conventional fossil fuel technologies that had an average total cost of electricity of 6.6 cents $/ \mathrm{kWh}$ in the U.S. Using the total of electricity net of emissions from Table 1, the relative cost of electricity from the new technologies is shown in

\footnotetext{
${ }^{10}$ The CES nesting structure for the advanced gas technology is similar to this, except that no factor inputs are required for the transport and storage of $\mathrm{CO}_{2}$ or fuel excluding $\mathrm{CO}_{2}$.
} 
Table 4, column 2. The advanced gas technology, at 1995 gas prices, is $16 \%$ cheaper than conventional fossil technologies. In the U.S., significant investments have been made in this technology since 1995, the base year of the data set. Rising natural gas prices have since slowed the expansion of this technology. The gas capture technology is marked-up $8 \%$ above the conventional fossil technology while the coal capture technology is marked-up by $25 \%$. These technologies are not economically viable absent the imposition of a carbon penalty in the form of a tax or emissions cap. The mark-ups of advanced gas, gas capture, and coal capture technologies are constant across all regions in EPPA ${ }^{11}$.

Using the emissions coefficients from Table 2, Equation 2 can be used to see how, from a partial equilibrium perspective, different generation technologies compare as the price of carbon changes, holding all other input prices constant. In particular, we can compute the carbon price that would be necessary to make the lower emitting technologies just competitive with conventional coal technologies or the advanced gas technology. These estimated break-even carbon prices, as compared with the advanced gas technology (the lowest cost alternative) and pulverized coal (the most ubiquitous conventional technology) are shown in the last two columns of Table 4. When compared with the advanced gas technology, and at the natural gas prices assumed above, the gas capture technology becomes competitive at $\$ 190 / \mathrm{tC}$ (tons of carbon), half that of the coal capture technology's equivalent price of $\$ 380 / \mathrm{tC}$. These carbon-equivalent prices drop substantially when the capture technologies are compared to pulverized coal technology, which at $0.21 \mathrm{~kg} \mathrm{C} / \mathrm{kWh}$ emits over twice as much carbon as the advanced gas technology. Evaluated against this technology, the gas capture technology becomes competitive at $\$ 35 / \mathrm{tC}$ while the coal capture technology is competitive at prices above $\$ 100 / \mathrm{tC}$. These differences further emphasize the importance of representing the best-available non-capture fossil technology if one hopes to correctly estimate the potential penetration of CCS technologies.

Table 4. Relative costs of electricity net of emissions

\begin{tabular}{|c|c|c|c|c|}
\hline \multirow[b]{2}{*}{ Technology } & \multirow{2}{*}{$\begin{array}{l}\text { Total Electricity } \\
\text { Cost Net of } \\
\text { Emissions Cost } \\
\text { (mills/kWh) }\end{array}$} & \multirow{2}{*}{$\begin{array}{c}\text { Cost of Electricity } \\
\text { Relative to } \\
\text { Conventional } \\
\text { Fossil }\end{array}$} & \multicolumn{2}{|c|}{$\begin{array}{c}\text { Carbon Entry Price } \\
(\$ / \mathrm{tC})\end{array}$} \\
\hline & & & $\begin{array}{l}\text { CCS vs. } \\
\text { NGCC }\end{array}$ & $\begin{array}{c}\text { CCS vs. } \\
\text { Conventional Fossil }\end{array}$ \\
\hline Conventional Fossil & 66.0 & & & \\
\hline Advanced Gas & 55.3 & $-16 \%$ & & \\
\hline Gas capture & 71.0 & $8 \%$ & $\$ 190$ & $\$ 35$ \\
\hline Coal capture & 82.3 & $25 \%$ & $\$ 380$ & $\$ 100$ \\
\hline
\end{tabular}

\section{Modeling Technology Adoption Rates}

The above sections describe a procedure for, and the challenges with, obtaining the correct relative economics for introducing non-extant technologies into CGE models. Yet, they do not address the rate of technology penetration - a critical factor in responding to constraints on greenhouse gas emissions. Evidence that a new technology gradually takes over a market such that the share of the market controlled by the technology plotted against time follows an S-

\footnotetext{
${ }^{11}$ Refer to McFarland, Reilly, and Herzog (2003) for a discussion of region-specific issues in CCS technology representation.
} 
shaped function, is widely observed (Geroski, 2000). Neither top-down, nor bottom-up models fully incorporate all of the agents or factors that generate this empirical behavior. This section presents an overview of the factors that influence the rate of technology adoption, examines the approaches taken to represent the penetration rates of CCS technologies, and suggests new areas of research for understanding and modeling the penetration rates of new technologies in integrated assessment models.

\subsection{Importance of technology adoption rates}

Both the rate and the magnitude of a technology's penetration into the market impact the extent and timing of the technology's benefits and the policy costs of reducing greenhouse gas emissions. Results of several modeling efforts suggest that the adoption of CCS technologies lowers the cost of $\mathrm{CO}_{2}$ emissions reductions. McFarland, Reilly, and Herzog (2003) illustrates that the adoption of CCS technologies in the electricity sector reduces the cost of stabilizing atmospheric greenhouse gas concentrations, at a level consistent with $550 \mathrm{ppm}$ of $\mathrm{CO}_{2}$, by several hundred dollars per ton of carbon. Kim and Edmonds (2000) shows a similar reduction in carbon prices under a $550 \mathrm{ppm} \mathrm{CO}_{2}$ stabilization scenario when CCS technologies because of CCS technology adoption in the electricity sector. In obtaining these substantial reductions in carbon prices both models presume that CCS technologies fully diffuse within five decades. This rate of adoption is aggressive when considered in a historic context. As Grubler et al. (1999) notes, technologies similar to CCS with expansive, networked infrastructures (e.g., electric power and natural gas) required six to eight decades to diffuse within a region. For this reason, a better understanding of the factors that influence these rates is valuable in formulating and evaluating climate policies.

\subsection{Factors affecting technology adoption rates and patterns}

Before discussing the methods employed by modelers to represent plausible rates of technology diffusion, we examine the broad set of factors that influence these rates. Synthesizing the seminal work of Rogers (1995), Blackman's (1999) review of the theoretical and empirical economic literature on technology diffusion, and Fine's (1998) work the evolution of industries and technologies, we present seven areas that influence technology diffusion: technology characteristics, adopter characteristics, declining technology costs, availability of information, industry characteristics, specialized resources, and general equilibrium effects.

Characteristics of the technology Perhaps the most obvious and expansive factor influencing technology adoption rates are the technology's characteristics - such as the expected returns and risk relative to existing technologies, the exclusivity of the technology's intellectual property, the degree and form of regulatory barriers, and the complexity relative to existing processes. High expected returns accelerate adoption while risk and regulation deter it. Proprietary positions may encourage or limit diffusion depending upon whether the supplier or the user of the technology holds the intellectual property. Complexity tends to deter adoption since the technology is difficult to understand, implement, or maintain. However, complexity of the existing system in which a technology functions may produce network externalities that make a technology more attractive. For instance, large-scale CCS power generating technologies benefit from the existing electricity transmission and distribution infrastructure. CCS technologies would be much less economically attractive if this infrastructure had to be installed, as is the case with hydrogen economy scenarios. 
Characteristics of potential adopters Empirical studies suggest that firms' size, access to credit, and quality of human capital influence technology adoption. Large firms tend to have a larger capital stock that increases the opportunities to replace aging capital and lowers the risk of investing in a novel technology. Rose and Joskow's (1990) study of electric utilities finds that large firms adopt new technologies earlier than small firms even after controlling for capital stock turnover. Firm's with older vintages of capital may find it more profitable to replace that capital with new technology. Heterogeneity across firms may contribute to the historic pattern of S-shaped technology adoption as the largest firms adopt first followed by the majority of midsized firms and finally by the smallest firms. Other theories contend that early adoption is more profitable since output prices return to a long-run equilibrium as more firms adopt the technology.

Declining technology costs McDonald and Schrattenholzer (2002) cite numerous studies of cost (and/or price) reductions in energy-related technologies. Costs may decline via several mechanisms: learning by doing, learning by using, economies of scale in production or unit size, and research and development by the supplier or adopter. Declining costs increase the relative economic advantage of a technology, thus promoting its adoption. This technology characteristic may explain the increasing rates of adoption in the early stages of technology diffusion. Initially, a technology may be economically attractive to only a small set of adopters. As costs decline, the technology appeals to a greater number of adopters. This process of adoption, production, and cost reduction is reinforced until it is no longer profitable for others to switch technologies.

Availability of information Early models of technology adoption were based on the concept that the dissemination of information explains diffusion (see e.g., Mansfield 1961). Similar to the spread of an epidemic, information spreads slowly from the first adopters then increases geometrically as the number of adopters grows. Adoption slows as the percentage of nonadopters declines. Taylor (2001) describes how information dissemination promoted adoption as well as learning in the development of $\mathrm{SO}_{2}$ scrubbers. The speed with which new technologies may be evaluated contributes to the amount and quality of available information. Unlike distributed generation technologies, for example, innovations in large-scale generating technologies typically require several years to test and evaluate.

Industry characteristics In addition to adopter characteristics, the economic benefits of acquiring a technology are dependent on the industry concentration, industry structure, and business cycle dynamics. The empirical basis of the effect of industry concentration is contradictory, perhaps reflecting countervailing processes. With relatively fewer firms, information flow is facilitated in concentrated industries, yet firm size tends to be highly variable in concentrated industries which tends to slow diffusion. The competitiveness of the firms supplying and supporting technologies encourages price reductions, and therefore, diffusion. Anex et al. (1999) note that the restructuring of the U.S. electric power sector promoted the adoption of less capital intensive advanced gas technologies. Business cycle dynamics may lead to erratic rates of investments and technology adoption. As evidenced by Ford (2001), the electricity generating industry is highly susceptible to such behavior. 
Specialized resources The production and operation of new technologies require specialized human or physical capital, such as engineers, tooling equipment or natural resources (e.g., suitable $\mathrm{CO}_{2}$ reservoirs), the supplies of which are limited in the short term. Thus the availability of these critical resources constrains the profitable level of technology adoption. Over time, the supply of these resources is increased or technology costs decline and adoption resumes.

General equilibrium effects Significant adoption of technologies that use a particular input will drive up the demand, and concomitantly, the price of that input. Likewise, as the adoption of new technologies drive output prices down, other firms are pressured to follow suit.

In attempting to represent technology adoption rates, models typically divide influences into two general camps: exogenous, absolute limits on production growth between two periods, and endogenous, where a desire to rapidly adopt the technology changes its cost either accelerating (learning) or hindering (adjustment costs) adoption. If left unconstrained, mathematical models exhibit unrealistically high rates of technology adoption. Applications of methods for limiting and accelerating adoption are discussed below.

\subsection{Exogenous Representations}

Exogenous representations typically limit either the maximum market share a technology may attain in a given year or the annual percentage growth rate a technology can achieve. Such constraints serve as a proxy for any and all of the factors limiting technology adoption. Manne and Richels (2002), in their assessment of the effects of learning on the timing of new technology adoption using the MERGE model, limit the production from new technologies in each region to $1 \%$ of total production in the year in which the technology is initially introduced. This limit increases by a factor of three for each decade thereafter implying that large-scale energy technologies require 40 years to supply $80 \%$ of the market. Consistent with this specification, the Dynamic New Earth 21 model limits CCS adoption in the electric power sector to $20 \%$ per decade (Yamaji, 2003). Johnson (2002) in a bottom-up cost optimization model of a U.S. electric grid constrains CCS adoption to roughly 5\% per year. For the purposes of longterm modeling, these exogenous approaches effectively replicate the empirical S-shaped adoption patterns. Yet such adoption limits are unresponsive to policy stringency.

\subsection{Endogenous Representations}

Endogenous representations incorporate feedback from one or more of the factors listed in Section 4.2. Thus if very stringent restrictions on $\mathrm{CO}_{2}$ are introduced suddenly, an endogenous adjustment cost constraint can allow rapid expansion of the technology, but with increasing costs. A simple exogenous constraint presents the same limits whether the price of carbon is $\$ 10$ or $\$ 500$ per ton. This section will examine the endogenous treatment of three factors influencing adoption rates in CGE models: specialized resource factors, capital vintaging, and capital malleability. Two other approaches, technology cost reduction through learning and adjustable supply curves will be also discussed.

\subsubsection{Specialized resouce factors}

An approach for representing the penetration process, that is theoretically consistent with CGE modeling, is to explicitly introduce an additional specialized resource as a factor of production, 
specific to the new technology, whose endowment in the economy is initially quite limited. In the context of large-scale electricity generating technologies, this specialized resource factor may be thought of as engineering capacity to build and install new plants that is initially limited but that increases in availability as the technology moves from the pilot plant stage to viable market competition. The price of this factor and its annual rents are determined endogenously, depending on its quantity relative to demand for the technology. As modeled, the factor endowment is initially limited but grows as a function of the technology's output. Additionally, an elasticity of substitution is specified within the CES production structure between the factor resource and the capital, labor, and energy bundle (see Figure 4) ${ }^{12}$.

To parameterize the growth of the specialized resource factor endowment, we consider the penetration rate of an analogous large-scale electric generating technology - nuclear power. During the rapid growth of nuclear power in the U.S., the market share of nuclear power expanded at an average annual rate of $45 \%$ per year at its nacency in the early 1970's dropping to $3 \%$ per year in the early 1990's. We parameterize the resource to limit the share growth of the new technologies, when faced with a carbon penalty of $\$ 200 / \mathrm{tC}$, to roughly mimic the historic share growth of nuclear power in the U.S. As long as output is growing, the endowment of this factor grows more than proportionally, and as it becomes less scarce, rents fall, and in the long run it does not restrict the ultimate penetration of the technology.

Unlike the exogenous limits approach, the use of a specialized resource factor incorporates a feedback mechanism that adjusts the rate of technology adoption based on the emissions penalty. An example using the parameterization above illustrates this feature. Under policies with carbon penalties in excess of $\$ 200 / \mathrm{tC}$, the technology adoption proceeds more rapidly. Although the price of the specialized resource factor rises due to scarcity, substitution is permitted between the resource factor and the bundle of other inputs allowing output to expand slightly above the parameterized path. One way to interpret this is that less skilled/specialized engineers and firms without experience can also produce capacity for the technology but their lack of experience means that it takes more labor and capital to build a plant. The additional output, relative to that observed in the $\$ 200 / \mathrm{tC}$ case, yields more specialized resource factor that is available in the next period since the factor endowment is a function of output. This incremental amount of resource expands output above the parameterized path in the next period and in all subsequent periods for which the technology is economically competitive. The opposite holds for less stringent policies.

\subsubsection{Capital vintaging and capital malleability}

Recognized as important aspects of the rate of technological change in the aggregate sectors (Jacoby and Sue-Wing, 1999), capital vintaging and malleability also affect both entry and exit rates of new technologies. Vintaging addresses the irreversible nature of physical capital investments and the life of the capital by tracking capital investments within a technology or sector over time until the investments are fully depreciated. Once vintaged capital is put in place it cannot be redeployed in another sector nor adjust to changes in relative prices within the limits of the CES production function, that is its factor shares are frozen at the values that were

\footnotetext{
${ }^{12}$ This elasticity of substitution is 0.2 . McFarland et al. (2003) contains a more technical and complete description of the specialized resource factor representation for CCS technologies in EPPA.
} 
simulated in the period the capital was put in place. Malleability denotes the ability of capital to be redeployed in other sectors of the economy and adjust to changes in relative prices.

In EPPA, four vintages of capital are defined. Given EPPA's 5-year time step, this vintaging structure means that capital has a lifetime of 25 years, five years as malleable capital when it is new investment and the following 20 years as vintaged capital. In the standard EPPA formulation, only some portion of the capital is vintaged. The remaining portion of old capital remains malleable and can be redeployed elsewhere in the economy with production characteristics dictated by the limits of the CES production functions describing each sector's technology. This representation makes no distinction between redeployment of capital from one sector to another (e.g., perhaps a structure being used in a different sector in succeeding periods) and retrofit (changing the technology characteristics, e.g., improving fuel efficiency or using a different fuel) of a facility that remains in the same production sector. While redeployment of capital to different sectors may in some cases seem reasonable it is surely limited. Fortunately, in applications of the EPPA model, it has proved rare to encounter a situation where sector to sector redeployment occurs. With a relatively highly aggregated and growing economy, and relatively gentle policy shocks demand for a sector's output was rarely simulated as declining from one period to the next by more than depreciation over the 5-year period. Thus, the old malleable capital rarely needed to be redeployed out of the sector, although the model makes no explicit accounting of where it ends up.

With the introduction of disaggregated technologies into the electricity sector, redeployment of capital became desired under many policy and price paths. The conditions that favored a desire to redeploy were the fact that the technologies produce a perfect substitute for one another, and with changing carbon policies relative costs of the technologies were altered in a short period. A technology that was economic in one period could be completely uneconomic in the next so that no production from it was desired. In this case, all of the old malleable capital could be redeployed elsewhere in the economy. In reality, it is difficult to imagine that much of the capital stock (e.g., turbines and pipelines) could be feasibly redeployed in other sectors of the economy.

To prevent redeployment but to continue to allow the idea of retrofit of facilities put in place in earlier years, we introduce a separate category of vintaged capital that remains malleable within the limits of the CES production function for the technology but that becomes sector specific. This revised approach includes four vintages that carry the production characteristics of the period in which they were put in place, a single additional vintage representing that portion of the undepreciated capital that remains malleable at the end of the period, and new investment. As specified, the sector can never decline more rapidly than depreciation, yet the malleable portion can be retrofit to adjust to changing relative prices. While most of the capital is rigid with fixed input shares, the malleable portion allows for the limited ability to modify electricity generation, transmission, and distribution processes.

To examine the effects of the vintaging and malleability structures on penetration rates of new technologies and on their rates of decline, we compare three cases: 
1. No capital vintaging for the new technologies. Capital investments in new technologies remain perfectly malleable across other technologies and sectors in the period subsequent to investment.

2. Technology-specific capital vintaging but with full malleability of capital within a specific technology (i.e., no rigid capital).

3. Technology-specific capital vintaging with $20 \%$ malleability ( $80 \%$ rigid) in the vintaged capital.

We report results from the reference scenario, with no emission penalties, and focus on the advanced gas technology.

The global output in trillion kilowatt hours (TkWh) of the advanced gas technology from 2000 to 2020 grows at different rates depending upon the vintaging and malleability assumptions. In the first case, output grows to $5.7 \mathrm{TkWh}$, or $26 \%$ of total electricity generation at an annual rate of $13 \%$ as shown in Figure 5. The second case, with technology-specific malleable capital reaches 6.6 trillion $\mathrm{kWh}$ exhibiting an average annual growth rate of $14 \%$. Output grows somewhat faster than in the first case because capital investments remain in the advanced gas technology until depreciated whereas the non-vintaged, fully malleable case permits capital investments to be moved to more productive uses in other technologies or sectors. The third case exhibits the slowest growth rates, only $11 \%$ per year. Since most of the capital is treated as rigid, the technology cannot adjust to changing input prices.

Rising natural gas prices arrest the output growth of the advanced gas technology under all three cases at different points in time and at different rates. As might be expected, the first case with no vintaging adjusts earlier, beginning after 2020, and faster, with a $6 \%$ rate of decline, than the other cases as capital is shifted to other sectors and technologies. With technology-specific vintaging and full malleability, output is not reduced until after 2025. Although the capital is fixed to the technology, it is able to adjust to changing relative prices. A slow output decline in the third case occurs after 2030 primarily due to the slow initial penetration rates.

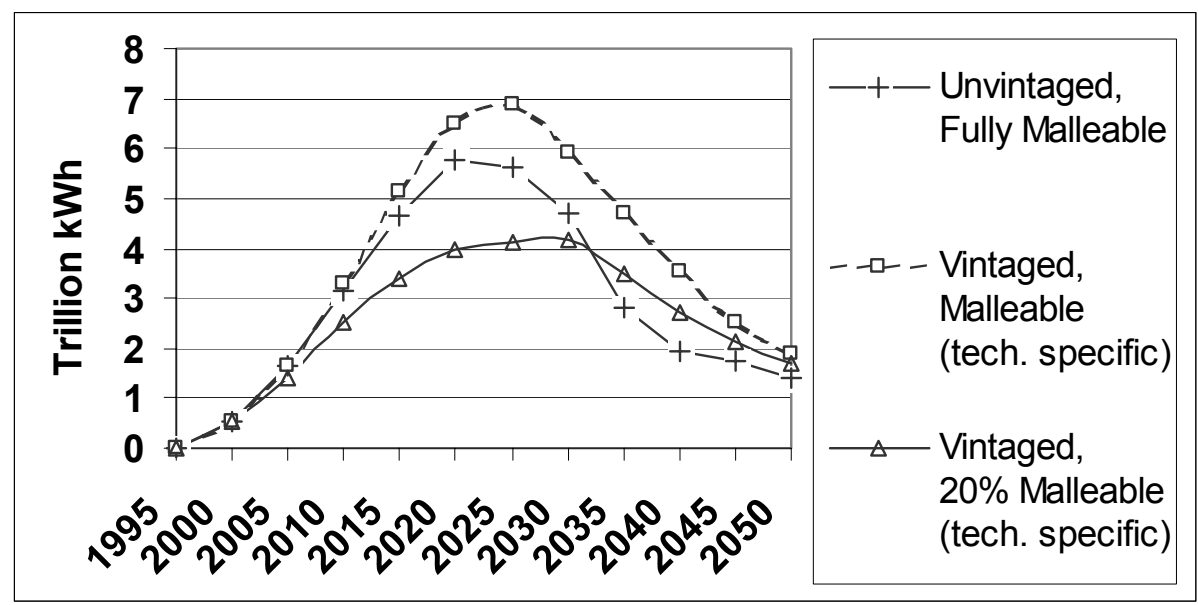

Figure 5. Effects of vintaging and malleability on advanced gas generation 


\subsection{3. $\quad$ Cost Reductions Through Learning}

Of the seven factors that influence technology adoption rates, learning is the most widely studied in the context of energy modeling and climate change. The incorporation of cost reducing feedbacks as a function of cumulative production in fully forward-looking models generate two important results. First, socially optimal investment paths indicate that technology adoption should occur before the technology becomes profitable for private firms. Second, this early and more rapid adoption lowers the cost of meeting greenhouse gas emissions constraints (Manne and Richels, 2002, Riahi et al., 2003). Jacoby, Reilly, and McFarland (2003) describes the effects of learning in a recursive dynamic model.

The use of learning specifications in economic models introduces two related issues: uncertainty and explanatory power. Significant uncertainties exist in the specification of the learning curves used in models including uncertainties of initial cost, learning rate, change in the learning rate as a function of cumulative production, and the long-run cost of technologies. These uncertainties apply to extant technologies and are magnified for non-extant ones. Although learning curves may describe general cost reducing trends, the aggregation of numerous effects that reduce costs into an equation does little to explain the many underlying processes that influence to cost reductions over time as noted in Section 4.2 and in McDonald and Schrattenholzer (2002). While descriptive power may be sufficient for very long-term projections, it is not necessarily adequate to inform the direction of policies that seek to alter technology adoption rates.

\subsubsection{Adjustable supply curves}

Partial equilibrium energy-economy models may incorporate a combination of short-run and long-run supply curves to represent scarcity of specialized resources and stable or declining long-run costs (see e.g., Edmonds and Reilly, 1983). The modeler's specify the long-run cost of the technology, a long-run growth rate for the technology, and short-run supply curves. As long as technology adoption occurs at the long-run rate, the long-run technology cost is maintained. If, however, optimal technology adoption is above the equilibrium growth path, a steeper, shortrun supply curve is employed to drive the price above the long-run level and reduce demand for the technology. Like the specialized resource factor approach, this method enables economic, lower-emitting technology to respond to emissions penalties by expanding output more rapidly than the long-run growth rate.

Figure 6 illustrates this method for a two-period example. A technology becomes competitive at prices above $P_{\min }$. In the first period, prices of the technology's output remain below the longrun price $P^{*}$ unless output expands beyond $Q_{t=1}^{*}$ at which point short-run costs drive the price above the long-run level. By the second period, the short-run supply curve has shifted out permitting output of $Q^{*}{ }_{t=2}$ before prices rise above $P^{*}$. 


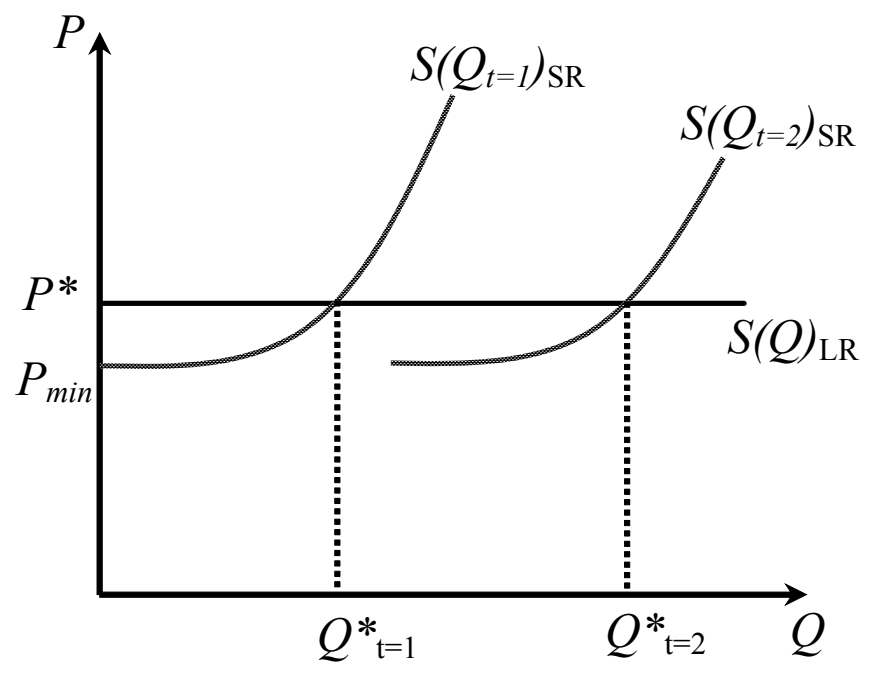

Figure 6. Adjustable supply curve approach to limiting technology adoption rates

\subsection{Research Direction}

All of the above approaches generate S-shaped adoption curves and several endogenously capture some of the critical factors that effect technology adoption rates. While most of the emphasis to date has been correctly placed on understanding the relative economic advantage of the technology and representing complex system issues such as dispatch. The three forms of endogenous constraints to technology adoption incorporate limits on specialized resources, capital vintaging and malleability, and learning, incorporate additional factors that effect adoption rates. However, these approaches ignore a majority of the factors that theoretically or empirically impact diffusion rates. Table 5 illustrates the factors that have been considered, but these are relatively few compared to the number of factors described in Section 4.2.

Table 5. Summary of Adoption Rate Factors Endogenously Represented in Economic Models

\begin{tabular}{|l|l|}
\hline \multicolumn{1}{|c|}{ Adoption Rate Factors } & \multicolumn{1}{c|}{ Section Reviewing the Representation } \\
\hline Technology Characteristics & Bottom-up costs (2.3), Relative costs (3.3), Dispatch (3.3) \\
\hline Adopter Characteristics & Capital vintaging (4.4.2) \\
\hline Declining Costs & Cost reduction through learning (4.4.3) \\
\hline Information Availability & \\
\hline Industry Characteristics & \\
\hline Special Resources & Specialized Resource Factors (4.4.1) \\
\hline General Equilibrium Effects & Factor shares (3.1), Substitution structure \& parameters (3.2) \\
\hline
\end{tabular}

Adopter characteristics such as firm size and firm heterogeneity cannot yet be consistently captured within the construct of a CGE model. Industry characteristics such as market concentration, supplier power, and business dynamics are also inconsistent with assumptions of perfect competition in CGE models and are below the level of model aggregation. Furthermore, the evolution of the regulatory regime surrounding CCS technologies (e.g., regulations governing $\mathrm{CO}_{2}$ transport, disposal, and liability) is not considered. The above approaches also neglect country and regional differences in technology adoption. While the first countries to adopt CCS 
technologies would likely experience significant uncertainties and hurdles, it is not immediately evident that subsequent countries would face the same limitations. The global reach of technology and energy service providers have strong incentives to disseminate information across borders. Additionally, areas of improvement exist in the current endogenous representations of adoption. For example, the dynamics of specialized resources within EPPA are based upon a proxy large-scale technology, nuclear power that requires different physical and human capital inputs and has more severe hazards.

To address these deficiencies in representing the diffusion of CCS technologies, we are developing a micro-level model of technology adoption in the electric power sector that capture. The objective of modeling these micro-level interactions is to develop a more plausible endogenous representation in top-down models such as EPPA both within a region and across regions. Adapting an approach used by Fine (2002) to understand technology adoption in the communications sector, we intended to examine the effect of five dynamic aspects of the fossil electricity and CCS value chains: technology, regulatory policy, the business cycle, industry structure, and corporate strategy. The fossil electricity value chain depicted in Figure 7 contains all industry segments from fossil fuel extraction through the end-user. Manufacturers of generating equipment are included since they are an important source of specialized human and physical capital. The CCS value chain encompasses reservoir exploration and development, $\mathrm{CO}_{2}$ capture, transport, and injection monitoring and storage.

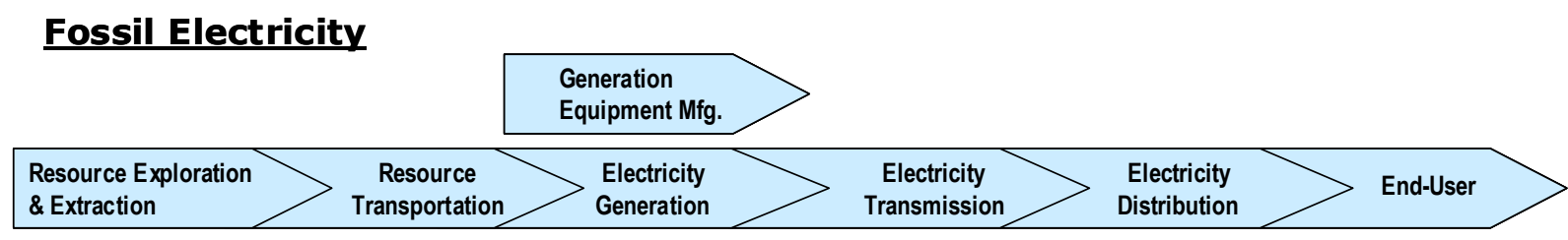

\section{Carbon Capture \& Storage}

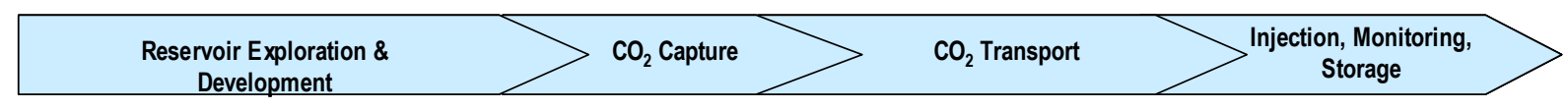

Figure 7. Value chains of electricity generation and carbon capture and storage

Each of the dynamic aspects addresses one or more of the factors affecting technology adoption rates outlined in Section 4.2:

1. Technology dynamics encompass costs, learning effects, and scale of both CCS technology and competing technologies.

2. Regulatory policy dynamics include policies that may limit diffusion such as siting, liability, and monitoring requirements and policies that promote adoption such as tax incentives, subsidies, and carbon penalties.

3. Business cycle dynamics addresses how the boom and bust cycles of capacity expansion in the electric power sector or in carbon transport and storage may influence adoption of CCS technologies. 
4. Industry structure dynamics evaluates the effects of the concentration of market power in the electric power industry, the potential for market power in the transport and storage segments, and the degree of heterogeneity among firms.

5. Corporate strategy dynamics consider the influence and behavior of firms with significant strategic influence on technology prices. One potential effect of this dynamic includes the pricing policies of generating equipment manufacturers.

A more detailed model of CCS technology adoption will enable more explicit representations of the theoretical and empirical factors affecting adoption rates. Such a model will help identify the most influential factors and may provide offer insights into the magnitude of the uncertainties surrounding adoption rates. The factors, sensitivities, and uncertainties gleaned from a microlevel model can then be used to improve the representation of technology adoption rates in topdown economic models.

\section{Conclusions}

We described a consistent method for incorporating CCS technologies into the EPPA model, a top-down CGE model using bottom-up engineering information. By defining consistent cost model boundaries that compare homogenous goods, the methodology is applicable to other technologies not widely available today. We identified plant level of dispatch as a critical component of electricity cost given the high capital costs of generating technologies. We showed how the translation of bottom-up engineering information into CGE models involves the specification of factor shares, elasticities of substitution, and relative economics.

Theoretical and empirical studies of technology diffusion suggest numerous factors that cause the market share of a technology plotted against time to follow an S-shaped curve. We presented an endogenous method for generating S-shaped adoption patterns consistent with CGE models based on short-run limitations on specialized resources. We further demonstrated that capital vintaging, capital malleability, and learning impact adoption rates. We also note that despite our ability to mimic empirical adoption curves, further research is needed at the industry and firm levels to develop more confidence in representations of technology adoption and its responsiveness to carbon constraints. To that end, we are in the process of developing a microlevel model of the dynamic nature of technology adoption in the electric power sector that identifies critical feedbacks and informs the parameterization of macroeconomic integrated assessment models.

\section{Acknowledgements}

This work was conducted with support by the US Department of Energy, Office of Biological and Environmental Research [BER] (DE-FG02-02ER63473).

The EPPA model used in much of this analysis was supported by the US Department of Energy, Office of Biological and Environmental Research [BER] (DE-FG02-94ER61937) the US Environmental Protection Agency (X-827703-01-0), the Electric Power Research Institute, and by a consortium of industry and foundation sponsors. Thanks are due to Henry Jacoby and John Reilly for their invaluable insights and comments on earlier drafts. 


\section{References}

Adelman, M.A. and M.C. Lynch, 2002. Natural gas supply to 2100, International Gas Union, October.

Anex, R.P., Velnati, S., Meo, M., Ellington, R. and Sharfman, M., 1999. innovation and thetransformation to clean technologies: life cycle management of gas turbine systems. Proceedings of the 1999 NSF Design \& Manufacturing Grantees Conference, Long Beach,CA, January 5-8.

Babiker, M., J. Reilly, M. Mayer, R. Eckaus, I. Sue-Wing, and R. Hyman, 2001, The emissions prediction and policy analysis (EPPA) model: update, sensitivity, and comparison of results, Report no.71, Joint Program on the Science and Policy of Global Change, MIT, Cambridge, MA.

Blackman, A. (1999). The economics of technology diffusion: implications for climate policy in developing countries. Resources for the Future, Discussion Paper 99-42, June.

Bock, B., R. Rhudy, H. Herzog, M. Klett, J. Davison, D. De La Torre, D. Simbeck, 2003, Economic evaluation of $\mathrm{CO}_{2}$ storage and sink enhancement options, TVA Public Power Institute Technical Report, February.

David, J. and H. Herzog, 2000, The cost of carbon capture, presented at the Fifth International Conference on Greenhouse Gas Control Technologies, Cairns, Australia.

Edmonds, J. and J. Reilly (1983). A long-term global energy-economic model of carbon dioxide release from fossil fuel use. Energy Economics, April, 74-88.

Fine, C.H., 2002. Roadmapping the communications value chain. presented at the Innovations in Management: Leadership, Management \& Innovation, Cambridge, Massachusetts, 8-9 May.

Fine, C.H., 1998. Clockspeed: Winning Industry Control in the Age of Temporary Advantage, Reading Massachusetts: Perseus Books.

Ford, A., 2001, Conservation in an Era of Boom and Bust, presented at the Conference on Conservation or Crisis: A Northwest Choice, Portland, Oregon, 24 September.

Fujii, Y. and K. Yamaji, 1998. Assessment of technological options in the global energy system for limiting the atmospheric $\mathrm{CO}_{2}$ concentration. Environmental Economics and Policy Studies, I:113-139.

Geroski, P.A., 2000. Models of technology diffusion, Research Policy 29, 603-625.

Grübler, A., N. Nakićenović, and D.G. Victor, 1999. Dynamics of energy technologies and global change, Energy Policy 27:247-280 
Hertel, T., 1997. Global trade analysis: modeling and applications, Cambridge, UK: Cambridge University Press.

IPCC, 2001. Climate change 2001: mitigation: contribution of working group III to the third assessment report of the intergovernmental panel on climate change, Metz, B., Davidson, O., Swart, R., and Pan, J., eds., Cambridge, UK: Cambridge University Press.

Jacoby, H.D., J.M. Reilly, and J.R. McFarland, 2003. Technology and technical change in the MIT EPPA model, P.I. Workshop, U.S. DOE Integrated Assessment Program, Snowmass, CO, 5-6 August.

Jacoby, H.D. and I. Sue-Wing, 1999. Adjustment time, capital malleability and policy cost, The Energy Journal, Special Issue: 73-92.

Johnson, T.L., 2002, Ph.D. Thesis, Carnegie Mellon University, Pittsburgh, PA.

Johnson, T.L. and D.W. Keith, 2003. Fossil electricity and $\mathrm{CO}_{2}$ sequestration: how natural gas prices, initial conditions and retrofits determine the cost of controlling $\mathrm{CO}_{2}$ emissions. Energy Policy (in press).

Kim, Son H., and James A. Edmonds. 2000. Potential for Advanced Carbon Capture and Sequestration Technologies in a Climate Constrained World. Washington, DC: Pacific Northwest National Laboratory Report No. 13095.

Manne, A. and R. Richels, 2002. The impact of learning-by-doing on the timing and costs of $\mathrm{CO}_{2}$ abatement, Working Paper, June.

Mansfield, E., 1961. Technical change and the rate of imitation, Econometrica, 29:741-765.

McDonald, A. and L. Schrattenholzer, 2002. Learning curves and technology assessment. International Journal of Technology Management 23(7/8):718-745.

McFarland, J.R., H.J. Herzog, and J.M. Reilly, 2003. Representing energy technologies in topdown economic models using bottom-up information, Energy Economics (forthcoming).

Prinn, R., H. Jacoby, A. Sokolov, C. Wang, X. Xiao, Z. Yang, R. Eckhaus, P. Stone, D. Ellerman, J. Melillo, J. Fitzmaurice, D. Kicklighter, G. Holian, and Y. Liu. Integrated global system model for climate policy analysis: feedbacks and sensitivity studies, Climatic Change 41(3/4): 469-546.

Riahi, K., E.S. Rubin, M.R. Taylor, L. Schrattenholzer, and D. Hounshell, 2003. Technological learning for carbon capture and sequestration technologies, Energy Economics (forthcoming).

Rogers, E.M., 1995. Diffusion of Innovations, $4^{\text {th }}$ ed., New York: The Free Press. 
Sands, R., 2003. Dynamics of carbon abatement in the second generation model. Energy Economics (forthcoming).

Speakes, K., 2002. Peaking generation: the emerging need for intermediate peaking power, Power and Gas Marketing, March-April.

Taylor, M.R., 2001. The Influence of Government Actions on Innovative Activities in the Development of Environmental Technologies to Control Sulfur Dioxide Emissions from Stationary Sources. Ph.D. Thesis, Carnegie Mellon University, Pittsburgh, PA, Jan. 2001.

U.S. Department of Energy, 1999. Supporting analysis for the Comprehensive Electricity Competition Act.

van der Zwaan, B.C.C., R. Gerlagh, G. Klaassen, and L. Schrattenholzer, 2002. Endogenous technical change in climate change modeling, Energy Economics 24, 1-19.

Weyant, J.P and J. Hill, 1999. Introduction and overview, The Energy Journal, Special Issue: vii-xliv.

Yamaji, Y. personal correspondence, June, 2003. 